\title{
Discours
}

Revue de linguistique, psycholinguistique et informatique. A journal of linguistics, psycholinguistics and computational linguistics

$1 \mid 2007$

Varia

\section{Setting the background in discourse}

Nicholas Asher, Laurent Prévot and Laure Vieu

\section{OpenEdition}

\section{Journals}

Electronic version

URL: http://journals.openedition.org/discours/301

DOI: $10.4000 /$ discours.301

ISSN: 1963-1723

\section{Publisher:}

Laboratoire LATTICE, Presses universitaires de Caen

\section{Electronic reference}

Nicholas Asher, Laurent Prévot and Laure Vieu, «Setting the background in discourse », Discours

[Online], 1 | 2007, Online since 12 May 2008, connection on 19 April 2019. URL : http://

journals.openedition.org/discours/301 ; DOI : 10.4000/discours.301

\section{(c) $($ i) $(9)$}

Discours est mis à disposition selon les termes de la licence Creative Commons Attribution - Pas d'Utilisation Commerciale - Pas de Modification 4.0 International. 


\title{
Setting the background in discourse
}

\author{
Nicholas Asher ${ }^{1}$, Laurent Prévot ${ }^{2}$, Laure Vieu ${ }^{1,3}$ \\ ${ }^{1}$ IRIT, CNRS, Toulouse \\ 2 ERSS, CNRS, Toulouse \\ ${ }^{3}$ LOA, ISTC-CNR, Trento
}

\begin{abstract}
Backgrounding relations play a crucial role in discourse and occur frequently in both written and oral corpora. These relations come in two flavors: either the background is introduced after or before the foreground (respectively Background $d_{b a c k w a r d}$ and Background forward ). In Segmented Discourse Representation Theory or SDRT [Asher and Lascarides, 2003], backgrounding relations were among the first to be considered [Lascarides and Asher, 1993]. However, while [Vieu and Prévot, 2004] have recently done a careful study of Background backward on the whole much less attention has been dedicated to Background forward situations. Our approach for Background forward $_{\text {fuilds on the }}$ SDRT analysis of locative adverbials in IP-adjunct position proposed in [Vieu et al., 2005]. Such locative adverbials, which have the ability to locate not only the sentence but a whole segment, introduce a complex discourse structure. In a nutshell, this structure contains a new discourse topic (framing topic), which is elaborated by the constituent representing the sentence or the discourse segment falling intuitively under the scope of the adverbial. We propose in this paper to use this mechanism to treat in a uniform way a wide range of phenomena that raise difficulties for a coherent and general treatment of Background $d_{\text {forward }}$ configurations.
\end{abstract}

\section{Résumé}

Les relations d'arrière-plan jouent un rôle important dans le discours et sont très fréquentes dans les corpus tant oraux qu'écrits. Ces relations existent sous deux formes: l'arrière-plan apparaissant avant ou après le premier plan (respectivement appelées Background $_{\text {forward }}$ et Background backward $_{\text {ba }}$. La relation d'arrière-plan a été parmi les premières étudiées dans le cadre de la SDRT de [Asher and Lascarides, 2003] et a bénéficié d'études complémentaires dans [Vieu and Prévot, 2004]. Cependant, le gros de ces travaux concerne Background backward $_{\text {alors que Background }}$ forward est relativement méconnue. La similarité de sa fonction discursive avec les adverbiaux locatifs antéposés nous a conduit à traiter Background $d_{\text {forward }}$ sur la base des solutions proposées pour ces derniers [Vieu et al., 2005]. Ces adverbiaux dont le pouvoir locatif dépasse les frontières de la phrase introduisent des structures discursives complexes. En résumé, cette structure est composée d'un nouveau topique discursif (topique cadratif) qui est élaboré par le constituant de la phrase suivante (ou le constituant complexe du segment). Nous exploitons ici ce mécanisme pour traiter uniformément les différents cas où les relations d'arrière-plan de type Background forward $_{\text {apparaissent. }}$ 


\section{Introduction}

Backgrounding relations play a crucial role in discourse and occur frequently in both written and oral corpora. The example (1) comes from a novel, (2) from a newspaper and (3) from a route explanation monologue recorded for psycho-linguistic studies. While Background is simply one among 14 relations retained in the Discor project [Reese et al., 2007], in the context of this discourse annotation campaign Background has been used by annotators as much as $23 \%$ of the time. ${ }^{1}$ Moreover backgrounding relations are important for structuring text, because their use allows to isolate the foreground, the main events that will help summarize the main line of a text. They are typically used for setting the stage of an event or a sequence of events like examples (1) or (2). But they are also involved for propositions introducing elements in the background of actions, for example landmarks in the case of route explanation like (3).

(1) Le cabinet du directeur était long, sombre, tranquille et climatisé.

Derace Kingsley s'introduisit vivement derrière les huit cent dollars de son bureau directorial et appliqua son postérieur sur un grand fauteuil de cuir. [...] Raymond Chandler. La dame du lac, chap 2 (translated by Boris and Michèle Vian).

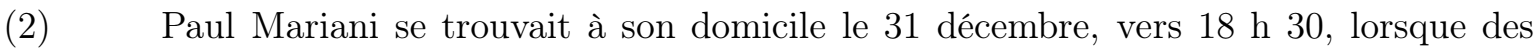
gravillons ont été jetés contre la fenêtre. Le village était alors plongé dans l'obscurité en raison d'une coupure de courant. $[\ldots]^{2}$

(3) [...] Vous tournez à droite, vous faites 30 mètres. Vous avez un feu. Il y a un passage piéton. Vous le traversez. $[\ldots]^{3}$

To account for the all the aspects of these relations, we need a framework able to address all the levels of the discourse analysis. Segmented Discourse Representation Theory or SDRT [Asher, 1993, Asher and Lascarides, 2003] provides such a framework. This theory, in the tradition of dynamics semantics, aims at bringing the benefits of formal compositional semantics to discourse analysis.

We will begin by introducing our formal framework (Section 2). Then, in Section 3 we will consider another approach of background and present some prior work on the subject. We will then focus on the analysis of one kind of Background: the forward-looking Background. We will start by presenting a perhaps naive but seductive hypothesis in Section 4 before discarding it and introducing a more sophisticated approach in Section 5. Section 6 will present our proposal in detail, and will show how to solve a number of situations occurring with Background relations. Before concluding in Section 8, we will present the analysis of a more complete example (Section 7).

\footnotetext{
${ }^{1}$ The Discor project is conducted under the auspices of an NSF project at the University of Texas. See http://comp.ling.utexas.edu/discor/ for further information. The first author thanks the NSF for partial support in writing this paper.

${ }^{2}$ Thanks to Marianne Vergez-Couret for providing us the text, extracted from "Le Monde" where we found this example.

${ }^{3}$ Thanks to Karine Ricalens for providing us her corpus of route explanation monologues.
} 


\section{The framework}

\subsection{Requirements}

Segmented Discourse Representation Theory (SDRT) is a theory that offers a formal account of the hypothesis that discourse has a hierarchical structure upon which interpretation depends. For our purposes we need the following features of SDRT (see for details, [Asher, 1993, Busquets et al., 2001, Asher and Lascarides, 2003]):

- SDRT's semantic representations or logical forms for discourse, SDRSs, are recursive structures. A basic SDRS is a labeled logical form for a clause, and a complex SDRS will involve one or more discourse relation predications on labels, where each label is associated with a constituent, i.e., a basic or a complex SDRS.

- An SDRS for a discourse is constructed incrementally within a logic of information packaging that uses several information sources and that is responsible for the final form of the SDRS. The logic of information packaging, or Glue Logic, which reasons about the structure of SDRSs, is distinct from the logic of information content, in which we formulate the semantic consequences of an SDRS. ${ }^{4}$

- The rules for inferring discourse relations are typically rules that exploit a weak (nonmonotonic) conditional >. They form part of the Glue Logic, which allows us to "glue" new constituents together with discourse relations to constituents in the given discourse context.

- The discourse relations used in SDRT, which have definite semantic (e.g. spatio-temporal, causal, etc.) effects, are binary and either coordinating or subordinating (see [Asher and Vieu, 2005]). An example of subordinating relations is Elaboration, where the second constituent, which can be complex, describes in more detail some aspect of some eventuality or some fact described in the first constituent. The overall structure of SDRSs is often represented as a graph in which coordinating relations are represented as horizontal edges, and subordinating relations as vertical ones. The link between a complex constituent and its sub-constituents is marked by dashed edges.

- The structure induced by all the edges in such a graph allows to visualize the so-called right frontier, the path that goes from the last label up to the topmost constituent. The right frontier is the basis for the expression of an important constraint in discourse. The right-frontier constraint governs both anaphora resolution, defining which referents are available, and possible discourse continuations, characterizing the nodes open for attaching new constituents.

- Some coordinating relations like Narration (where constituents describe a sequence of events) and Continuation (where linked constituents bear some common, single relation to another constituent) require a topic; i.e., there must be a basic constituent that summarizes the two related constituents and that is linked to a complex constituent containing them via the subordinating Elaboration relation. If this third constituent has not been explicitly given in the previous discourse, it must be "constructed", i.e., abstracted from the elements of the complex constituent it dominates. In this case, it

\footnotetext{
${ }^{4}$ See [Asher and Lascarides, 2003] for a presentation of these two levels.
} 
is necessary to update the logical form of the topic constituent each time the complex constituent is extended [Asher, 2004].

\subsection{Discourse and temporal structure}

Discourse structure affects the resolution of underspecified elements in the semantics. For instance, sometimes the temporal structure of a discourse is more elaborate than what is suggested by a semantic analysis of tenses (such as that found in DRT [Kamp and Reyle, 1993]). There are clearly temporal shifts that show that the treatment of tenses cannot simply rely on the superficial order of the sentences in the text. Consider the following discourse (from [Lascarides and Asher, 1993]).
a. John had a great evening last night.
b. He had a great meal.
c. He ate salmon.
d. He devoured lots of cheese.
e. He then won a dancing competition.

The part (4c-d) provides 'more detail' about the event in (4b), which itself elaborates on (4a). (4e) continues the elaboration of John's evening that (4b) started, forming a narrative with it (temporal progression). Clearly, the ordering of events does not follow the order of sentences, but rather obeys the constraints imposed by discourse structure, as shown graphically below in Figure 1. Thus the eventualities that are understood as elaborating on others are temporally subordinate to them, and those events that represent narrative continuity are understood as following each other.

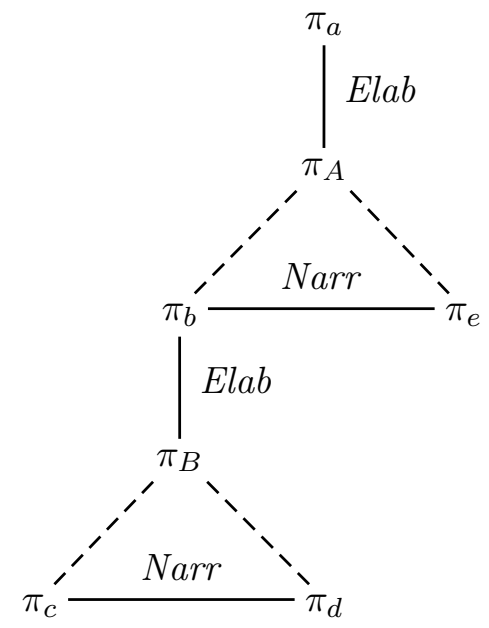

Figure 1: SDRT graph for example (4)

The relevant parameter for interpreting tenses is discourse adjacency in the discourse structure, not superficial adjacency. A theory like SDRT [Asher, 1993, Asher and Lascarides, 2003] provides the discourse structure of Figure 1 for (4) and allows us to correctly analyze the tenses. For clarity purposes we will identify labels of complex constituents with capital letters 
$\left(\pi_{A}, \pi_{B}, \ldots\right)$ while labels of simple constituents will be indexed by lowercase letters $\left(\pi_{a}, \pi_{b}\right.$, ...) corresponding to the letters indexing the examples, and implicit basic constituents such as constructed topics will be identified by numbers $\left(\pi_{1}, \pi_{2}, \ldots\right) .{ }^{5}$ The label $\pi$ is the (usually complex) constituent corresponding to the whole discourse (it includes all other constituents).

\subsection{Underspecification}

Temporal relations between events introduced by verbs with certain tenses are underspecified in a language like English, and discourse structure is an important clue to resolving this underspecification. SDRT hypothesizes that many types of semantic underspecification are similar: ellipsis [Asher et al., 2001], pronominal anaphora [Asher, 1993], and presupposition [Asher and Lascarides, 1998, Asher and Lascarides, 2003]). To see how this comes about, we need to think a little harder about discourse coherence and its relation to discourse structure. In SDRT, as in most theories of discourse interpretation, to say that a discourse is (minimally) coherent is to be able to derive a discourse structure for it. Discourse coherence is a scalar phenomenon, however. It can vary in quality. Roughly speaking, discourse coherence is maximized by 'maximizing' the rhetorical connections and minimizing the number of underspecified conditions. A principle governs decisions about where one should attach new information when there's a choice. It also governs decisions about how other forms of underspecification get resolved. The principle states that the preferred updated SDRS always maximizes discourse coherence or $M D C$ [Asher and Lascarides, 2003]. The $M D C$ principle plays a role distinct from the axioms in the Glue Logic for inferring discourse relations in SDRT. $M D C$ is a way of choosing the best among the discourse structures allowed by the axioms in the Glue Logic. We won't be much concerned here with exactly how discourse relations are inferred, but we will need from time to time to refer back to this underlying logic.

\section{The background on background}

According to the survey proposed in [Hovy and Maier, 1995], many theories include a background relation: [Hovy, 1990], [Hobbs, 1979], SDRT [Lascarides and Asher, 1993], RST [Mann and Thompson, 1987], [Paris, 1990]. In this section we will look more particularly at the RST (Rhetorical Structure Theory) proposal before turning back to the SDRT account of Background.

\subsection{Background in Rhetorical Structure Theory}

In RST, discourse constituents are divided among nuclei and satellites. The nuclei are essential for understanding the discourse while the satellites are somehow less important and always dependent on a nucleus. Background information is situated in a satellite reflecting the idea that the backgrounded information is peripheral to the main storyline.

Def 1 Background in RST [Carlson and Marcu, 2001]

Background: [...] the satellites provides information that helps the reader understand the

\footnotetext{
${ }^{5}$ The clear distinction between these constituents and their respective behavior in the discourse interpretation process suggests moreover the need for introducing in SDRS language these different types of discourse constituents. For example, such a move is needed for handling some kind of implicit constituent updates presented in Section 6.2.
} 
nucleus: The satellite is not the cause/reason/motivation of the situation presented in the nucleus. The reader/writer intentions are irrelevant in determining whether such a relation holds. In contrast with the Circumstance relation the information or the context is not specified clearly and not delimited sharply. Hence, the Circumstance relation is stronger than background. The background satellite establishes in other words the context or the grounds with respect to which the nucleus is to be interpreted. Understanding the satellite helps the reader understand the nucleus. Often, in a Background relation, the events represented in the nucleus and the satellite occur at distinctly different times, whereas events in a circumstance relation are somewhat co-temporal.

The RST definition (Def 1) of Background introduces interesting elements corresponding to the intuitions we would like to capture. The background that establishes the context or the grounds with respect to which the nucleus is to be interpreted also corresponds to the idea that the background sets the stage for the main storyline. However at the temporal level, the two theories diverge. SDRT considers that the eventualities involved in Background overlap temporally while RST uses this information to distinguish Background from Circumstance. This is however just a terminological issue; the RST relation we need to compare to SDRT's Background is not only Background $_{R S T}$ but also Circumstance $_{R S T}$ (Def. 2).

Def 2 Circumstance in RST [Carlson and Marcu, 2001]

In a Circumstance relation, the situation presented in the satellite provides the context in which the situation presented in the nucleus should be interpreted. The satellite is not the cause/reason/motivation of the situation presented in the nucleus. The reader/writer intentions are irrelevant in determining whether such a relation holds. Select Circumstance over Background when the events described in the nucleus and satellite are somewhat co-temporal.

The RST original proposal distinguishes subject matter and presentational relations and counts Background as one of the presentational relations while Circumstance is a subject matter one. However, the effect of presentational relations is rather imprecise: their "intended effect is to increase some inclination on the part of the reader" [Taboada and Mann, 2006]. As our goal is to provide a formal semantic account of discourse and as the notions involved at the "presentational" level are not well defined, we will need a more precise characterization based, among other elements, on spatio-temporal semantics. Moreover we consider that the stage (or frame) set by Background implies necessarily a temporal overlap between the eventualities involved. We therefore use our Background $d_{S D R T}$ relation for both Background ${ }_{R S T}$ and Circumstance $R S T$. The subject matter aspect is tackled by the semantic constraints of the relation while the presentational level corresponds to its structural behavior within discourse.

\subsection{Forward-looking and backward looking Background}

Backgrounding relations come in two flavors: either the background is introduced after the foreground (hereafter Background backward), as exemplified in (5) between (5b) and (5c) or in example (6); or it is introduced before $\left(\right.$ Background $\left._{\text {forward }}\right)$, as in between (5a) and (5b) or in (7).

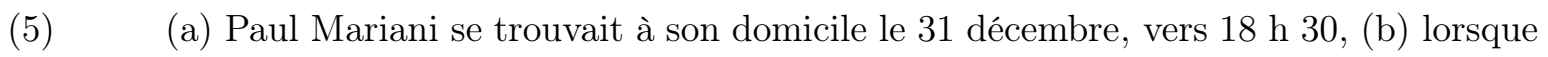
des gravillons ont été jetés contre la fenêtre. (c) Le village était alors plongé dans l'obscurité en raison d'une coupure de courant. [...] (repeated from 2) 
(6) (a) Mary came home. (b) It was pouring with rain.

(7) (a) It was pouring with rain. (b) Mary came home.

A Background relation corresponds to an alternation of clauses introducing states and events. A state, or potentially several ones, form the background-generally describing the setting of the action- while the event or sequence of events constitute the foreground. Therefore the difference between Background $d_{\text {backward }}$ and Background $d_{\text {forward }}$ comes from the order of occurrence of the clauses introducing the different kinds of eventualities. ${ }^{6}$

\subsection{Background in SDRT}

The earliest research in SDRT - see in particular [Lascarides and Asher, 1993] — uses Background to capture the spatio-temporal constraints that occur in examples well known from the DRT treatment of sequences of passé simple and imparfait tenses in French. A typical example of this phenomenon occurs in (8); DRT theorists argued that the imparfait introduces a state while the passé simple introduces an event that the state temporally overlaps.

(8) Marie entra. Paul lisait le journal.

In more recent research, SDRT has identified three prototypical uses of Background:

- To capture a specific spatio-temporal structure as in (6),(7) or (8), where Background requires an event / state sequence and there is a temporal overlap between these eventualities;

- To accommodate presuppositions in the discourse structure [Asher and Lascarides, 1998]. The idea is that presuppositions constitute a background for the interpretation of the asserted material.

- "To set the stage" of a story. This situation is more difficult to define but we will attempt to capture it in Section 6.

\subsubsection{Spatio-temporal structure}

In (8) the event of Paul's reading the newspaper temporally and spatially overlaps with the event of Mary entering; this temporal relation reflects the description of the Circumstance $_{R S T}$ relation. The SDRT account provides a more formal account than the description given by $R S T$, as illustrated by Definition 3. Nevertheless, there is more to Background than this temporal constraint. This may be related to what is said in RST about the "stage setting", as we will see below.

Def 3 Spatio-temporal effects of Background:

- Background backward $(\alpha, \beta) \rightarrow e_{\alpha} \circ_{t} e_{\beta}$

- Background $_{\text {forward }}(\alpha, \beta) \rightarrow e_{\alpha} \circ_{t} e_{\beta}{ }^{7}$

where $o_{t}$ is the temporal overlap relation between eventualities, and $e_{\alpha}$ is the main eventuality of the constituent $\alpha$.

\footnotetext{
${ }^{6}$ This simple idea becomes more complicated once we start to think about the nature of events and states, if any, described by clauses with true, generalized quantifiers. We leave this aspect for future research.

${ }^{7}$ Overlap being a symmetric relation, the spatio-temporal effects of Background $d_{\text {backward }}$ and Background $_{\text {forward }}$ are the same.
} 


\subsubsection{Presupposition accommodation}

Another important aspect of backgrounding relations in SDRT is to model the effects of accommodation of presuppositions. RST, not having been concerned with linguistic phenomena like presupposition and event structure, does not address these issues.

The King of France is bald $\rightarrow$ / There is a King of France /presup He is bald.

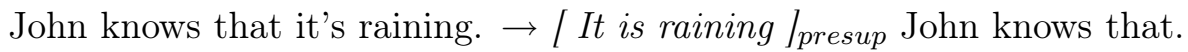

In examples (9) and (10), the presupposition is interpreted prior to the proffered content (the "asserted" component, though this last term is a misnomer) and thus in dynamic semantic frameworks provides appropriate antecedents for the anaphoric pronouns in the proffered content. These examples constitute a Background forward $_{\text {in }}$ [Asher and Lascarides, 1998]. The presuppositions also served as "scene setting", thus having the same presentational effects as normal Background backward .

\subsubsection{Setting the stage}

Although not precisely defined, this idea that backgrounds somehow set the stage for the main story or argumentation line is intuitively very important. In SDRT, this idea can be partially captured by the requirement of identifying a common topic between the background and the foreground, therefore rejecting examples like (11) because of the impossibility of building a common topic between the two constituents.

\section{? Jean fuma une cigarette. Marie avait les cheveux noirs}

A step towards this solution has been first implemented by a construction called the Focus Background Pair (or FBP). We will discuss this more complex account of Background backward in SDRT, first proposed in [Asher et al., 1995], in Section 3.5.

\subsection{Detecting Background}

Backgrounding relations have been found to be rarely marked [Knott, 1996, Marcu, 1997]. In [Marcu, 2000] lexical chains and cohesive relations rather than connectives are used for detecting Background. In SDRT, the triggering rules for Backgrounds mainly makes use of stative/eventive eventualities sequence as shown in Definition 4.

Def 4 SDRT Triggering rules for Backgrounds [Asher and Lascarides, 2003]

- $\operatorname{Event}\left(e_{\alpha}\right) \wedge \operatorname{State}\left(e_{\beta}\right) \wedge ?(\alpha, \beta)>$ Background $_{\text {Backward }}(\alpha, \beta)$

- $\operatorname{State}\left(e_{\alpha}\right) \wedge \operatorname{Event}\left(e_{\beta}\right) \wedge ?(\alpha, \beta)>$ Background $_{\text {Forward }}(\alpha, \beta)$

where ? $(\alpha, \beta)$ means that constituent $\beta$ is to be attached to constituent $\alpha$ by a still underspecified discourse relation.

Nevertheless, connectives like while or when and presupposition markers (9) are easily recognized triggers of Background forward structures. The Discor project uses these as clues for the annotation of Background $d_{\text {backward }}$ and Background forward $_{\text {relations. [Prévot, 2004] used }}$ the same idea, since he used specific markers such as lorsque or quand to infer "localization" structures which he treated as introducing backgrounding relations. 


\subsection{On the nature of background relations}

Early proposals in SDRT regarding Background (up to [Asher and Lascarides, 1998]) did not work out properly the constraints on anaphoric accessibility of discourse enti-

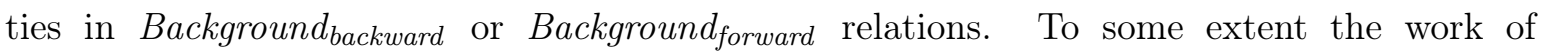
[Asher et al., 1995], later on reused in a generation setting in [Roussarie, 2000] and taken up in [Asher and Lascarides, 2003], on the Foreground Background Pair (FBP) construction remedied this. Indeed, the main motivation for the FBP proposal was to be able to account for sequences of background sentences, as in example (12), where the square (la place) in (12a) is the referent of the anaphoric pronoun in $(12 \mathrm{c})$.

(a) Yoann arriva aux abords d'une place près de la rivière. (b) Il pleuvait sans s'arrêter depuis une semaine. (c) Elle était complètement inondée.

The FBP proposal introduced a specific complex structure with a topic-like component, and a rule for making the foreground available for further backgrounds as illustrated in Figure 2. The proposal was based on the assumption made in SDRT from the beginning that Background $_{\text {backward }}$ is coordinating. However this treatment violated SDRT's right frontier constraint (this can be seen in Figure 2 itself, with two coordinating relations originating in the same node), and it demanded quite complex operations of discourse revision, since the FBP was a pair, not a standard constructed topic.

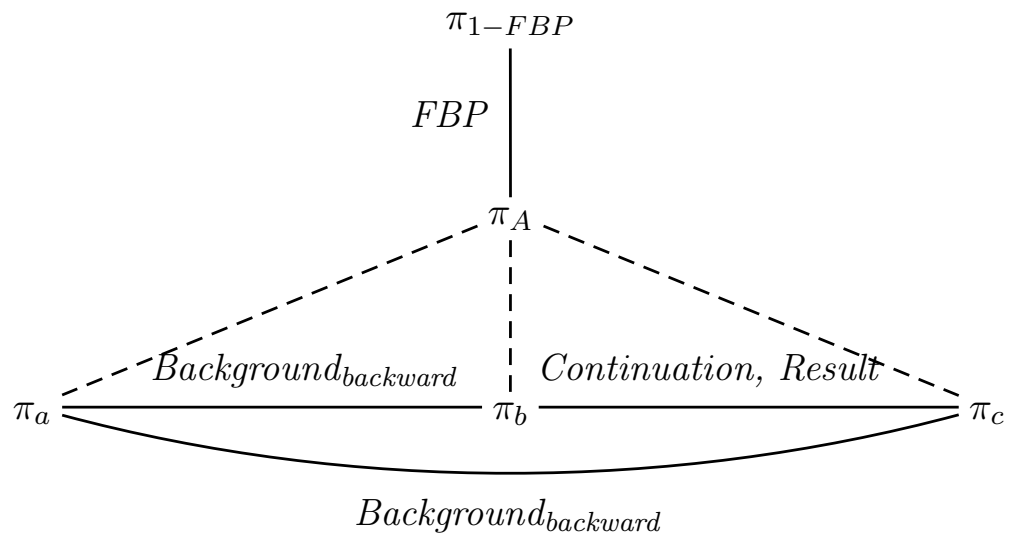

Figure 2: Structure for (12) with FBP

On the basis of [Asher and Vieu, 2005]'s study of subordinating and coordinating relations in SDRT, [Fabricius-Hansen et al., 2005] and [Vieu and Prévot, 2004] independently challenged the hypothesis that Background backward was coordinating. They propose an alter-

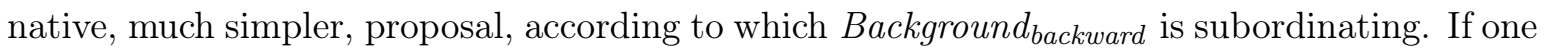
establishes, as is usually done, a correspondence between subordinating relations in SDRT and nucleus-satellite relations in RST, this proposal corresponds more closely to RST's assumptions

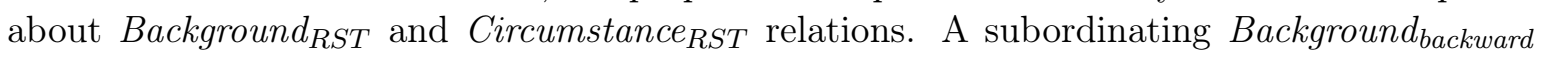
yields the structure given in Figure 3 for example (12). Overall, this choice resulted in a great simplification all the while preserving the advantages of the FBP solution. Nevertheless, 
neither [Fabricius-Hansen et al., 2005] nor [Vieu and Prévot, 2004] considered forward-looking Backgrounds. We now turn to these.

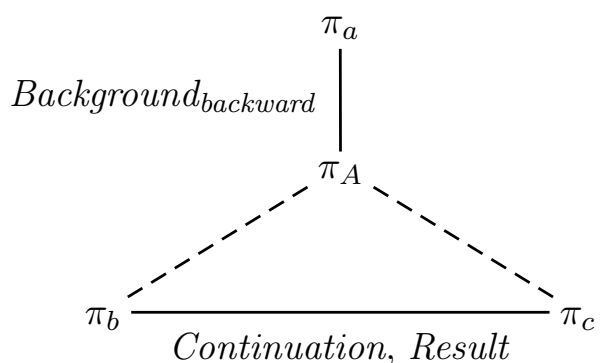

Figure 3: Structure for (12) with background subordinating

\section{A simple hypothesis about Background $_{\text {forward }}$}

\subsection{Argument switching?}

In the past Background $d_{\text {forward }}$ has often simply been replaced with Background $d_{\text {backward }}$, switching the order of the arguments. In corpus studies, we have found many relations in which argument switching turns out to be a useful simplification. For instance, the antecedent of a conditional in our examination of newspaper texts is often given after the introduction of the consequent-viz., we have something like $p$ if q. [Hunter et al., 2006, Reese et al., 2007] also found that Attribution or Source relations often introduced by communicative verbs must have their arguments "rearranged" in newspaper texts. Here is a typical and complex example from the ACE2 corpus of news texts:
a. If the Indonesian leader is to lure back the capital that has fled his country,
b. these officials argue,
c. he must not only follow the IMF's prescriptions,
d. but take political steps to inspire confidence among investors that Indonesia is headed on a long-term reform path that will minimize the risk of a social explosion. [...]

The source of the entire complex conditional, whose antecedent is given by (13a) and whose consequent is given by the complex constituent consisting of (13c) and (13d) linked by Parallel and Continuation, is given by constituent (13b). Thus, for such a structure, annotators agreed on an SDRS with the following conditions:

- $\pi_{A}:$ Continuation $\left(\pi_{c}, \pi_{d}\right) \wedge \operatorname{Parallel}\left(\pi_{c}, \pi_{d}\right)$

- $\pi_{B}:$ Consequence $\left(\pi_{a}, \pi_{A}\right)$

- $\operatorname{Source}\left(\pi_{B}, \pi_{b}\right)$ 


\subsection{A benign issue}

In order to square these argument reversals with the formalism of the Glue Logic of [Asher and Lascarides, 2003], one has to relax the information about attachment. All that is known typically in the inference to a rhetorical relation is that two constituents must be attached but it is not yet known by which relation. We can augment the underspecification and also assume the order is not known. This modification to the Glue Logic formalism introduces only a slight increase in underspecification, which the Glue Logic language is in any case designed to accommodate. It would seem then that we could eliminate Background $_{\text {forward }}$ with this simple strategy. It is one that fits in with SDRT's global use of underspecification and seems to be needed in any case to handle many other attested cases of discourse attachment.

\subsection{A major flaw}

There is, however, one fatal flaw in this proposal at least for the cases we are interested in. The flaw is a consequence of several well-founded assumptions. We take the proposal made by Asher and Lascarides [Asher and Lascarides, 1998] concerning presuppositions as attaching with Background to be essentially correct. But this means that material in the presupposition will not be typically available for anaphoric co-reference, once we have we have popped out of the backgrounded material. Let us consider a typical case of a presupposition that is attached with Background.

$$
\text { John's son is sick. }
$$

(14) gives rise to the following presupposed and proffered constituents:

- $\pi_{\text {pres }}: \exists x \operatorname{Son}(x, j)$

- $\pi_{\text {prof }}: \exists s(\operatorname{Sick}(s, x) \wedge \operatorname{State}(s))$

The rules for presupposition attachment along with our Simple Hypothesis will in this case imply that Background backward $\left(\pi_{\text {prof }}, \pi_{\text {pres }}\right)$. Given that, in SDRT, the scope of existential quantifiers on referent variables is established by dominance relations in the graph, in this case the variable $x$ in the proffered content will not be bound by the quantifier in $\pi_{\text {pres }}$ and have its value either chosen at random in $\pi_{\text {prof }}$ or will be undefined, which is not what we want. We need at the very least to have interpreted the presupposition prior to interpreting the proffered content, if we want to get anything like the right truth conditions or update conditions for such simple examples. Thus, staying with one Background relation where first the proffered content is interpreted and then the presupposed content is integrated is simply not an option. Asher and Lascarides assumed in effect Background forward $_{\text {as }}$ as distinct from Background backward $_{\text {b }}$ for precisely this reason.

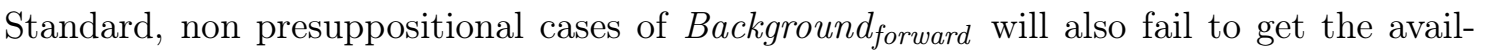
ability facts right if we combine the argument switching hypothesis with the idea that Background $d_{\text {backward }}$ is a subordinating relation. For example, this combination of strategies for (15) will yield Background $d_{\text {backward }}\left(\pi_{b}, \pi_{a}\right)$, which will predict that the man is no longer available for anaphoric co-reference given the SDRT rules for availability - the antecedent for the pronoun is in a constituent that is no longer on the right frontier of the graph, which recall is defined as the path from the last constituent entered to the highest or topmost constituent. 

a. A man was sitting on a bench.
b. A woman walked over to him.

This issue is not specific to the Background backward $_{\text {and }}$ Background $d_{\text {forward }}$ cases. Most relations could have an inverse, i.e., a relation which has the same semantic effects, but whose arguments are presented in inverse order. The question to introduce or not a specific relation for an inverse relation can be therefore raised for most existing discourse relations in SDRT.

For instance, Explanation and Result could be seen at the semantic level as inverse relations. At the causal level so far detailed in SDRT, the semantic effects of Explanation $(\alpha, \beta)$ are the same as the ones of $\operatorname{Result}(\beta, \alpha)$ as can be seen in Definition 5:

Def 5 Semantic effects of Result and Explanation: [Asher and Lascarides, 2003]

- Explanation $(\alpha, \beta) \rightarrow \operatorname{cause}\left(e_{\beta}, e_{\alpha}\right)$

- $\operatorname{Result}(\alpha, \beta) \rightarrow \operatorname{cause}\left(e_{\alpha}, e_{\beta}\right)$

Nevertheless, the hypothesis to treat both with a single relation and the argument switching mechanism has never been proposed in SDRT. And this was never done for good reason, we argue. These relations have incompatible structural properties. Explanation is subordinating while Result is by default coordinating. The order of appearance of the constituents they relate can strongly affect the structural nature of a discourse relation. It is dubious to treat systematically $R$ and $R^{-1}$ with a single relation which might hide the important differences between the two. ${ }^{8}$ We therefore consider argument switching not only inadequate at the technical level for binding effects but also at the informational level for establishing the right discourse structure.

\section{A new approach to Background forward $_{\text {f }}$}

In order to understand what our options are, let us look at Background forward $_{\text {configurations }}$ in more detail. A Background forward configuration can appear in various ways outside the case of presupposition as we have seen in previous examples. The background clause can be independent, as we have seen in (7) and (1) (now (17)), or a relative, as in (18) :

(17) Le cabinet du directeur était long, sombre, tranquille et climatisé.

Derace Kingsley s'introduisit vivement derrière les huit cent dollars de son bureau directorial et appliqua son postérieur sur un grand fauteuil de cuir. [...] (repeated from (1))

(18) While it was pouring with rain, Mary came home.

\footnotetext{
${ }^{8}$ Argument switching could be an adequate solution for handling the special case of subordinated clauses in which anaphora behaves differently as exemplified in (16). This approach might be justified on syntactic grounds.

(16) a. When a great man is happy, he always sings.

b. When he is happy, a great man always sings.

c. A great man always sings when he is happy.

d. * He always sings when a great man is happy.
} 
We agree with [Reese et al., 2007] that the temporal connectives while and when in anteposed adverbial clauses are markers of the Background forward $_{\text {relation, as well as gerund or }}$ gerundive phrases as in the example above. But adverbial clauses and sentence adverbials like in (19) are semantically very similar; indeed, some analyzes do not differentiate between them [Johnston, 1994, Maienborn, 1995].

During the downpour, Mary came home.

A further similarity between our Background $d_{b a c k w a r d}$ markers and locative sentence adverbials regards their forward-looking or "framing" character. [Charolles, 1997] convincingly argues that locative adverbials have the ability to locate not only the sentence but a whole discourse segment initiated by the modified sentence. And, as exemplified by (1), (3), or (26)

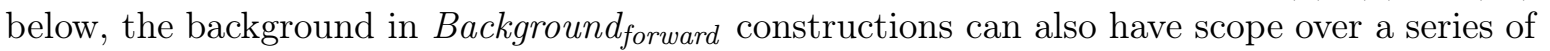
event reporting clauses. [Sarda, 2005] notes that in some cases (though not all) the framing character of the adverbial supplies the only coherence to the discourse that falls within its scope and thus supplies an essential discourse connectivity. In this too it functions like a SDRT discourse structure.

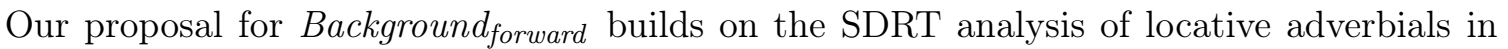
IP-adjunct position proposed in [Vieu et al., 2005, Vieu et al., 2006]. Such locative adverbials introduce a complex discourse structure. In a nutshell, this structure is composed of a new discourse topic, hereafter the Framing Topic or FT, which is elaborated by the constituent representing the sentence or a complex constituent corresponding to the discourse segment. The semantic component of the adverbial - its locative function - distributes over the eventualities of the topic and the elaborating constituents.

We postulate for the case of a Background $f_{\text {forward }}$ an FT as well, elaborated by the foreground clause(s). With a full backgrounding clause instead of an adverbial, a further constituent is inserted in addition to the FT. This constituent is simply related to the topic by the standard Background $d_{\text {backward }}$ relation. The structure obtained for the first two clauses of a simple example like (17) is given in Figure 4, while the full example, in which the scope of the background extends over the second and the third clause, is illustrated in Figure 5.

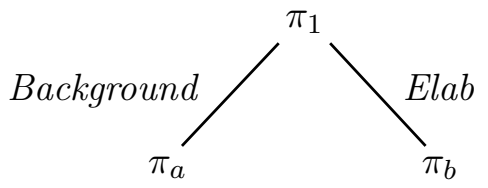

Figure 4: Structure for (17), first two clauses

One advantage of our proposal is that it does not augment SDRT with a new discourse relation. In fact, since a single relation will be used from now on, we will more simply write Background instead of Background backward. In some sense, we keep here the idea of reversed relations, that of not adding further relations. But we preserve the right structural properties regarding anaphora resolution and referent scope, as we will see shortly. And so doing, we also account for the peculiar forward-looking character of Background forward ${ }^{9}$

\footnotetext{
${ }^{9}$ The modification of the treatment of forward-looking background avoids the introduction of two Background
} 


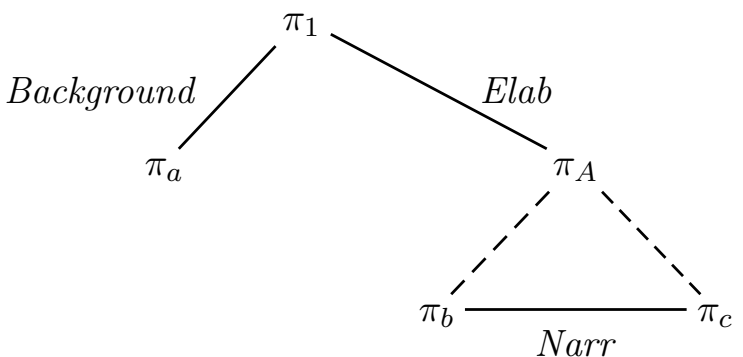

Figure 5: Structure for (17)

The complex structure obtained may seem similar to the FBP construction, since one could argue the FBP topic and the Framing Topic are both constructed topics. However, there is an important difference. The Background relation is no longer established between $\pi_{b}$ and $\pi_{a}$, but between the FT and $\pi_{a}$. Another difference is that the FT is a standard constructed topic, and not a pair which requires an ad-hoc revision procedure.

The criticism we made towards the complexity of the FBP structure may well be repeated here, however. Indeed, it may seem a bit awkward to build a constructed topic when a simple constituent elaborates it, i.e., when the foreground is not a complex constituent describing a sequence of events, but a simple one. Nevertheless, there is no straightforward way to simplify this picture. If one wants to account for the framing character of Background forward $_{\text {, }}$, one needs to have, right from the start, a construction which is extensible. And, above all, eliminating the FT when there is only one foreground clause boils down to a Background backward with switched arguments. And we have seen in Section 4 that the Simple Hypothesis is very problematic.

Let's sum up our proposal regarding the existence of two different Background relations. We propose a single Background relation although we still distinguish the two situations by differentiating the discourse structures in which the relation appears. A backward-looking background situation will simply introduce two constituents linked by the Background relation. A forward-looking background situation will introduce a more complex structure with an additional Framing Topic constituent linked to the background by a Background relation and to the foreground by an Elaboration.

We will now examine our proposal in more detail to show how it avoids the pitfalls of the simple argument switching hypothesis.

relations. However this simplification is at the cost of a more subtle SDRT topic management. Indeed, our proposal creates a new case where implicit discourse topic constituents need to be introduced. We believe however that this new treatment is justified by the main characteristics of forward-looking background. Such discourse segments tend to require a storyline or an event for which they play a background role. Moreover, their scope is not established at the time they are produced, as this depends on subsequent discourse. Therefore, our construction using a discourse topic to which following discourse elements might or might not be attached seems particularly attractive, regardless of the fact that in addition it avoids the use of two different Background relations. 


\section{Using the framing topic for treating forward-looking back- grounds}

\subsection{Triggering the FT structure with Background $_{\text {forward }}$ constructions}

It is relatively easy to trigger the introduction of the framing topic for examples like (18) where the discourse marker signals the specific structure. This is less straightforward when the only clue is the aspect of the clauses starting a discourse as in (7). Two strategies come to mind: (i) discourses starting with stative clauses systematically introduce a background frame for a foreground to come, (ii) the framing topic structure is introduced only once an eventive clause (the foreground) is interpreted and attached to a previous stative one (the background). The first option is both in the spirit of the "forward-looking character" of frame adverbials and in line with anaphoric - in this case, cataphoric - analyses of the imparfait, while the second option is more in keeping with SDRT hypotheses and algorithms.

We follow here the second strategy for reasons of simplicity. As will be seen at the end of this section, Background forward constructions do not only occur in discourse beginnings, and this makes it much more complicated to implement the first option. For this second strategy to work, we assume that stative clauses in a discourse initiating sequence are related by relations of Continuation, while the next eventive clause, the foreground, is to be attached preferably to the complex constituent grouping all the statives, which then generates the FT structure.

\subsection{Framing topic content}

Determining the precise content of the Framing Topic constituent (FT), in particular the amount of background contents that is needed in it, is of prime importance for making the correct prediction of referent availability. When locating adverbials occur in IP-adjunct position, [Vieu et al., 2005] show that the content of the framing topic is the "propositionalization" of the adverbial. This is obtained through existential closure over the $\lambda$-abstracted variables in the formula corresponding to the semantics of the adverbial, whose standard syntactic position is assumed to be VP-adjunct. ${ }^{10}$ The general form of the semantic content of locating adverbials is expressed in (20) [Vieu et al., 2005, p.176]:

$$
\lambda P \lambda e(P(e) \wedge \phi(e))
$$

where $\phi$ correspond to the locative contribution, $e$ is a variable that has to be bound by an eventuality (at the inflection node) and $P$ is the predicate given by the VP.

The IP-adjunct position induces an existential closure over the lambda-abstracted variables, resulting in (21) [Vieu et al., 2005, p.184]:

$$
\exists P \exists e(P(e) \wedge \phi(e))
$$

This implies that the eventuality that the adverbial helps locate, which is characterized by the VP when the adverbial is in VP-adjunct position, is in the framing topic at first left underspecified.

The discursive, forward-looking, character induced by the IP-adjunct position is then realized through the SDRT mechanism of topic construction, which successively abstracts over

${ }^{10}$ The differences between these positions is not taken as one of semantic content [Vieu et al., 2005, p.178]. 
the properties of the eventualities of the constituents elaborating the FT, in the end replacing the predicate variable $P$ by the calculated property as described in [Asher, 2004].

As far as the Framing Topic in Background forward constructions is concerned, we want to keep this forward-looking character, but we obviously have to drop the locative contribution of the adverbial. At first sight, the initial content of the FT is thus simply:

$$
\exists P \exists e P(e)
$$

The foreground is the first constituent elaborating the FT, which is therefore updated, and the variable $P$ substituted for the property characterizing the event in the foreground, with necessary additional referents "moving" from the foreground to the FT.

In addition to have its eventuality regularly updated by the properties of the eventualities of the subsequent foregrounding constituents, the FT for Background $d_{\text {backward }}$ is more complex than for locative adverbials, as some material from the background also percolates up to the FT.

This is a general characteristic of constructed topics, which have the particularity of taking some discourse referents from the nodes below and making them go higher in the discourse structure - viz, into the constructed topics. We think that percolation most clearly applies to material introduced by presuppositions: all the discourse referents introduced in a presupposed constituent percolate up to the FT. In the case of a standard Background forward $_{\text {construction }}$ between proffered contents, only some elements appear able to percolate upward. Our current hypothesis is that information structure [Vallduví, 1994, Asher and Gómez Txurruka, 1995, Steedman and Kruijff-Korbayova, 2001] and the position of the referring expressions on the givenness scale [Prince, 1981, Gundel et al., 1993] affect the potential of a referent to percolate up to the topic. In addition, factors like syntactic or thematic role can affect this potential; for instance, referents in subject position are often more salient and are available for co-reference in the foreground, as in example (15). Such an hypothesis has been already posited within Centering theory [Grosz et al., 1995] where the subject is very highly ranked as a center of the discourse. In any case the factors that affect percolation are not peculiar to the framing topics built for forward-looking backgrounds. The same issues arise with narrative topics, as can be seen in example (23-23') where the pronoun it is able or not to pick the referent this bench / a bench. However, deciding precisely on which referents percolate and which do not is an issue that goes far beyond the scope of this paper.

(a) I really liked this bench in the park. (b) Some kids came into the park last night.

(c) and they put graffiti and garbage all over it. (d) It is ruined.

(a) There is this guy I know, yesterday he sat on a bench in the park. (b) Some kids came into the park last night. (c) ?? and they put graffiti and garbage all over it. (d) ?? He liked it a lot and he is now very sad.

To sum up, we assume that all the presupposed material percolates to the topic (the standard approach in theories of presupposition that take discourse structure into account) but only the most salient referents of proffered content background clauses go to it as well. ${ }^{11}$ Let's note that the quantification over referents percolating in the topic has to be removed from the constituents they were originally to be moved at the level of the topic constituent.

\footnotetext{
${ }^{11}$ Note that for presupposition, some ambiguity is left concerning attachment: as is well-known [van der Sandt, 1992, Beaver, 1997, Asher and Lascarides, 1998], presuppositions may attach in situ or higher in the discourse structure. The Maximize Discourse Coherence principle takes care of this.
} 


\subsection{Two simple examples}

Let's first take a look at how our proposal handles cases of simple presupposition accommodation. Consider again the constituents derived from (14):

- $\pi_{a-p r e s}: \exists x \operatorname{Son}(x, j)$

- $\pi_{a-p r o f}: \exists s(\operatorname{Sick}(s, x) \wedge \operatorname{State}(s))$

Let us suppose, as explained before, that the presence of $\pi_{a-p r e s}$ triggers a complex Background $_{\text {forward }}$ structure with a framing topic. Our framing topic is originally the one given in the formula (22). It is then updated by the contents of the proffered constituent $\pi_{a-p r o f}$ to bound the variable $P$, and by the referent $x$ of the presupposed constituent $\pi_{a-\text { pres }}$ that percolates up. The SDRS $\pi$ that we end up with has three basic sub-constituents related in the following way.

- $\pi$ : Background $\left(\pi_{1}, \pi_{a-\text { pres }}\right) \wedge \operatorname{Elab}\left(\pi_{1}, \pi_{a-\text { prof }}\right)$

- $\pi_{1}: \exists x \exists s(\operatorname{Sick}(s, x) \wedge \operatorname{State}(s))$

- $\pi_{a-p r e s}: \operatorname{Son}(x, j)$

- $\pi_{a-p r o f}: \exists s(\operatorname{Sick}(s, x) \wedge \operatorname{State}(s))$

Within this structure, there is now no problem of the availability of referents, John's son $(x)$ has percolated up to the topic $\pi_{1}$ so it is able to bind the variable in both the proffered and the presupposed constituents. Note that the variable $P$ has disappeared from the FT and that the FT was updated by the properties of the main eventuality in the proffered constituent.

The second simple example we consider is a standard Background forward $_{\text {construction, like }}$ (24).
a. A man was sitting on a bench.
b. A woman walked over to him. (repeated from (15))

The resulting structure is the following, where $\pi_{1}$ is the framing topic:

- $\pi$ : Background $\left(\pi_{1}, \pi_{a}\right) \wedge \operatorname{Elab}\left(\pi_{1}, \pi_{b}\right)$.

- $\pi_{1}: \exists x, z, e($ Walk-over-to $(e, z, x) \wedge \operatorname{Event}(e))$

- $\pi_{a}: \exists y, s(\operatorname{Sit-on}(s, x, y) \wedge \operatorname{Man}(x) \wedge \operatorname{Bench}(y) \wedge \operatorname{State}(s))$

- $\pi_{b}: \exists t, e($ Walk-over-to $(e, z, t) \wedge \operatorname{Woman}(z) \wedge t=x \wedge \operatorname{Event}(e))$

The anaphora is resolved without any problem, as the referent $x$, the subject of the background, has percolated up into the FT. This structure easily allows the extension of the story by a further sentence continuing the foreground. The scope of the background would then automatically be extended by the standard SDRT procedure of topic update, based on a generalization of the eventualities in the constituents elaborating the FT. 


\subsection{Forward-looking backgrounds and composite constituents}

Problems arise when we deal with series of background clauses and series of foregrounds. In example (25) if we consider only the main clauses we have a series of two stative clauses (a-b) followed by a series of three eventive clauses (c-e). Both stative clauses together describe a single scene that serves as a background for the successive events described by the following three clauses.

(a) Rien n'était si beau, si leste, si brillant, si bien ordonné que les deux armées.

(b) Les trompettes, les fifres, les hautbois, les tambours, les canons, formaient une harmonie telle qu'il n'y en eut jamais en enfer. (c) Les canons renversèrent d'abord à peu près six mille hommes de chaque côté; (d) ensuite la mousquèterie ôta du meilleur des mondes environ neuf à dix mille coquins qui en infectaient la surface.

(e) La baïonnette fut aussi la raison suffisante de la mort de quelques milliers d'hommes. [...] Chapter 3 of Candide (Voltaire)

We first examine how our proposal accounts for the background developed over several clauses, and then consider what happens when the foreground is complex.

\subsubsection{Composite backgrounds}

Let's consider the first three sentences in example (25). The construction of the corresponding SDRS starts by attaching $\pi_{b}$ to $\pi_{a}$ by a Continuation relation. When attempting to attach the third clause to the complex constituent so created, a framing topic is inserted; and the resulting SDRS is then the following (we simplify somewhat the propositional content of each clause and disregard the presupposition induced by the first definite):

- $\pi$ : Background $\left(\pi_{1}, \pi_{A}\right) \wedge \operatorname{Elab}\left(\pi_{1}, \pi_{c}\right)$

- $\pi_{1}: \exists e, x, t, u($ Knocked-off $(e, t, u) \wedge \operatorname{Event}(e))$

- $\pi_{A}$ : Continuation $\left(\pi_{a}, \pi_{b}\right)$

- $\pi_{a}: \exists s_{a}\left(\operatorname{Army}^{*}(x) \wedge \operatorname{Two}(x) \wedge \operatorname{State}\left(s_{a}\right) \wedge \operatorname{Beautiful}\left(s_{a}, x\right) \wedge \ldots \wedge \operatorname{Orderly}\left(s_{a}, x\right)\right)$

- $\pi_{b}: \exists s_{b}, y 1, y 2, y 3, y 4, y 5, z\left(\right.$ Trumpet $^{*}(y 1) \wedge \ldots \wedge$ Canon $^{*}(y 5) \wedge \operatorname{State}\left(s_{b}\right) \wedge$ Harmonious $\left.\left(s_{b}, y 1 \oplus y 2 \ldots \oplus y 5\right) \wedge O f(y 1, z) \wedge \ldots \wedge z=x\right)$

- $\pi_{c}: \exists e_{c}, v\left(\right.$ Canon $^{*}(t) \wedge \operatorname{Man}^{*}(u) \wedge 6000(u) \wedge$ Knocked-off $\left(e_{c}, t, u\right) \wedge \operatorname{Event}\left(e_{c}\right) \wedge O f(t, v) \wedge$ $v=x)$

which can be graphically represented as in Figure 6 .

As far as the semantic effects of Background are concerned, with this structure and the principle of distributivity of relations over complex constituents, we get: $s_{a} \circ_{t} e \wedge s_{b} \circ_{t} e$, as expected. 


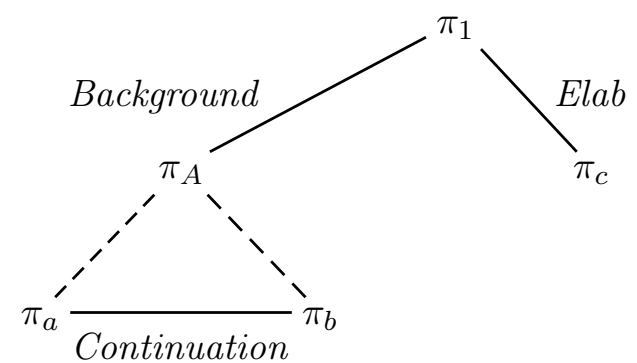

Figure 6: Structure for first three sentences of example (25)

\subsubsection{Composite foregrounds}

Sequences of foregrounding sentences are as frequent as sequences of backgrounding clauses. The last three sentences of (25) all describe eventualities happening within the same setting. Examples with even longer sequences of events situated by a single Background relation abound, as in example (26).
A trois cent mètres de la barrière, un chemin étroit couvert de feuilles de chêne sèches datant de l'automne précédent contournait une falaise de granit et disparaissait derrière. Je le pris, rebondis sur les cailloux sur une trentaine de mètres, puis rangeai la voiture près d'un arbre en tournant le capot dans la direction d'où je venais. J'éteignis les phares. Je coupai le contact et j'attendis. [...]
Raymond Chandler. La dame du lac, chap 12 (traduit par Boris et Michèle Vian)

We have already anticipated the solution for such examples in Section 5, as they fully justify a use of FT. The graph of the SDRS for the full example (25) is given in Figure 7. The contents of the FT $\pi_{1}$ is successively updated to yield the following:

- $\pi_{1}: \exists e, x, t_{1}, t_{2}, t_{3}, u_{1}, u_{2}, u_{3}\left(\operatorname{Killed}\left(e, t_{1} \oplus t_{2} \oplus t_{3}, u_{1} \oplus u_{2} \oplus u_{3}\right) \wedge \operatorname{Event}(e)\right)$

where $t_{1}$ are the canons and $u_{1}$ the men described in $\pi_{c}, t_{2}$ and $u_{2}$ the artillery and the men in $\pi_{d}$, and $t_{3}$ and $u_{3}$ the bayonets and the men in $\pi_{e}$.

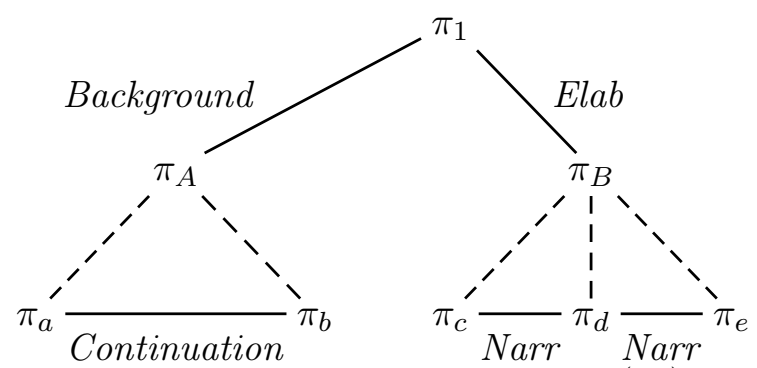

Figure 7: Structure for example (25)

\subsection{Entangled structures}

Matters get even more complex when series of stative and eventive clauses are intertwined, giving rise to successions of Background $d_{b a c k w a r d}$ and Background ${ }_{\text {forward }}$ relations. 


\subsubsection{Eventive clauses between two stative clauses}

Let's first focus on the case of eventive clauses occurring between two stative clauses. If we consider (27), a simplified version of (2), both background states contribute to set the stage of the event. The construction detailed above predicts that a framing topic is introduced for $(27 \mathrm{a}-\mathrm{b})$. The following state, in the absence of more specific information such as a new adverbial (something that will be examined in Section 6.6), can be attached with a Background relation again to the FT as illustrated on Figure $8 .{ }^{12}$

(a) Paul Mariani se trouvait à son domicile, (b) lorsque des gravillons ont été jetés contre la fenêtre. (c) Le village était alors plongé dans l'obscurité en raison d'une coupure de courant. [...]

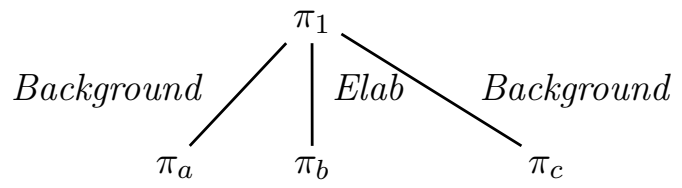

Figure 8: Discourse structure for example (27)

The structure obtained matches our basic intuitions about this example. As far as the semantic effects are concerned, we do get, as expected, that the event in $\pi_{a}$ - which is at this point simply a copy of the event in $\pi_{b}$ - temporally overlaps both states described in $\pi_{a}$ and $\pi_{c}, s_{a}$ and $s_{c}\left(e_{b} \circ_{t} s_{a} \wedge e_{b} \circ_{t} s_{c}\right)$.

One could go even further and introduce a mechanism for expressing the spatio-temporal relations between the different constituents forming the background of a framing topic, be they grouped together in a complex constituent, as seen in Fig. 7, or split, as is the case here. For example here, we might want to add an overlap relation between $s_{a}$ and $s_{c}$. However, we leave this possibility open for future work.

\subsubsection{Stative clauses between two eventive clauses}

The previous section considered the case where two pieces of background surrounded an event. We now turn to the reverse situation where a single background serves for two eventives as illustrated by example (28).
a. A woman walked into the waiting room.
b. A man was sitting on a bench.
c. She walked over to him.

In this example $\pi_{b}$ plays a background role both for $\pi_{a}$ and for $\pi_{c}$ and there is a Narration relation between $\pi_{a}$ and $\pi_{c}$ since they are constituting two steps of the same story.

The constituent $\pi_{b}$ is attached as usual with the regular Background relation to $\pi_{a}$. But we construct a framing topic when attaching $\pi_{c}$ to $\pi_{b}$, so we assume that the FT is substituted for the constituent $\pi_{c}$ in the Narration relation of this example. We then end up with the following SDRS and the structure illustrated by Figure (9).

\footnotetext{
${ }^{12}$ Actually, the constituent $\pi_{b}$ is also open for attachment so that $\pi_{c}$ could be attached there as well. We will not examine further that hypothesis; we may assume that MDC will rank the structure we have retained here as more coherent.
} 
- $\pi_{a}: \exists x, y, e_{a}\left(\right.$ Walk-into $\left.\left(e_{a}, x, y\right) \wedge \operatorname{Woman}(x) \wedge \operatorname{Waiting-room}(y) \wedge \operatorname{Event}\left(e_{a}\right)\right)$

- $\pi_{b}: \exists z, t, s_{b}\left(\operatorname{Sit-on}\left(s_{b}, z, t\right) \wedge \operatorname{Man}(z) \wedge \operatorname{Bench}(t) \wedge \operatorname{State}\left(s_{b}\right)\right)$

- $\pi_{c}: \exists u, v, e_{c}\left(\right.$ Walk-over-to $\left.\left(e_{c}, u, v\right) \wedge u=x \wedge v=z\right)$

- $\pi_{1}: \exists u, v, e($ Walk-over-to $(e, u, v))$

- $\pi_{A}: \operatorname{Background}\left(\pi_{a}, \pi_{b}\right) \wedge \operatorname{Background}\left(\pi_{1}, \pi_{b}\right) \wedge \operatorname{Elab}\left(\pi_{1}, \pi_{c}\right) \wedge \operatorname{Narration}\left(\pi_{a}, \pi_{1}\right)$

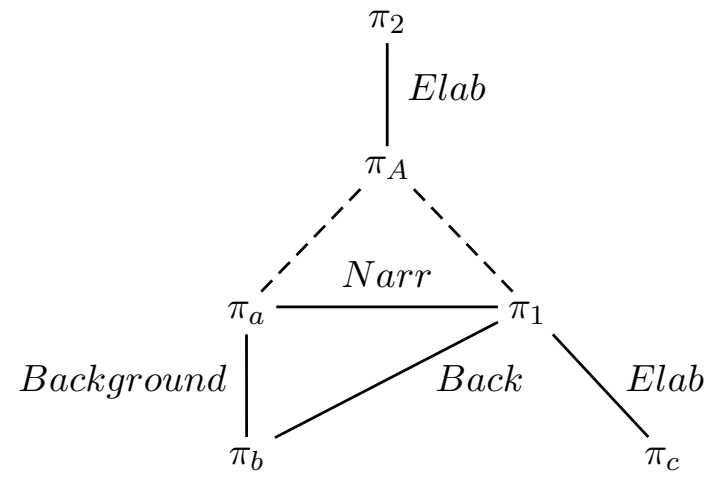

Figure 9: Structure for example (28)

Note that while the FT $\pi_{1}$ is attached both to $\pi_{a}$ and $\pi_{b}$, this does not constitute a violation of the Right Frontier, as prior to the attachment $\pi_{a}$ and $\pi_{b}$ are both open.

Similarly, but in another context, Background forward $_{\text {structures }}$ are frequent in route explanation dialogues (and monologues) where significant sub-dialogues are setting the stage (typically introducing and describing landmarks) for instructions. In such cases, the background often seems to relate to both the previous and the following foregrounds (e.g (29)). In [Vieu and Prévot, 2004] these cases have been treated with a combination of Background $_{\text {backward }}$ and Background $d_{\text {forward }}$ relations. The solution proposed above and illustrated in Figure 10 constitutes a more coherent solution for such situations.
a. Vous tournez à droite,
b. vous faites 30 mètres
c. vous avez un feu
d. il y a un passage piéton
e. $\quad$ vous traversez [...] (repeated from (3))

A further issue concerns the scope of the framing topic. In example (29), the signal lamp and the pedestrian crossing are in the background of the crossing instruction (29e). However, in case of a continuation with a further event such as (29f) "et 100 mètres après vous arriverez à la gare" ("and 100 meters later you will reach the station"), we would like to account for the intuition that the setting installed does not concern the station. So here, (29f) should not be attached to (29e) under the FT. Although we have not performed a systematic study 


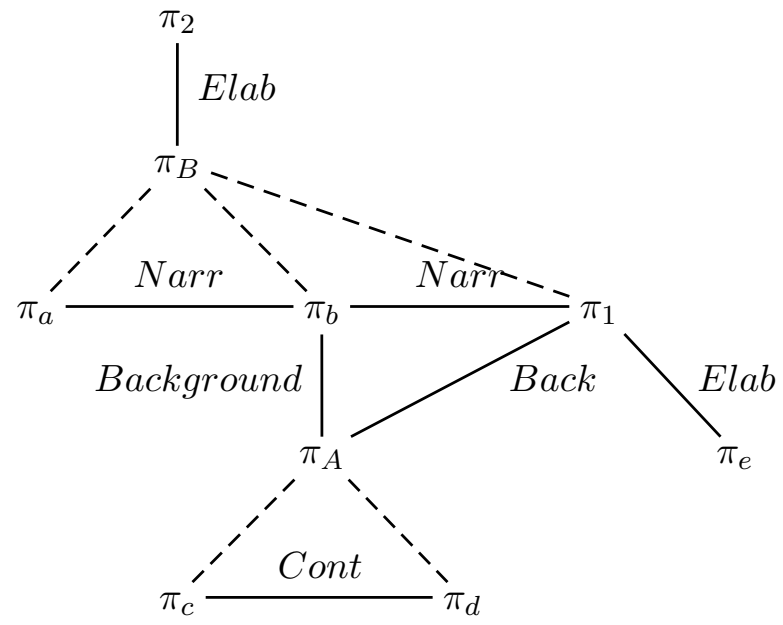

Figure 10: Structure for example (29)

of this problem, we believe that [Le Draoulec and Péry-Woodley, 2001] already provides an important step toward its resolution. In that paper, the authors establish a series of clues for detecting rupture at the framing level. These clues are (i) incompatible adverbials, (ii) tense change and (iii) paragraph change. In our example, clues (i) and (ii) are present and will exclude the arrival at the station from the framing topic, which includes the landmarks. To succeed in this task, it is clear that a relatively sophisticated spatio-temporal theory is required in order to determine the incompatibility of the adverbials.

We now turn to considering how to deal with adverbials within background structures.

\subsection{Adverbials within the backgrounded clause}

In our analysis of Background forward we have used the idea of a framing topic originally introduced for sentential locative adverbials. The question now is: what happens when we have

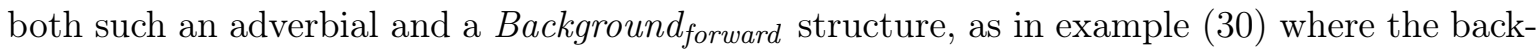
ground is itself located by an adverbial. Such constructions are extremely frequent and raise a new issue for our account. We have to figure out how to avoid a proliferation of constructed topics. In other words, we must determine how to decide that two potential framing topics are corresponding to the same level of discourse structuring. In (30), the framing topic introduced by the adverbials should be the same as the one corresponding to the background. The situation is located temporally and the background facts appear to be located in this temporal frame. Together, these two elements provide a single setting for the following event.

(a) Le 31 décembre, vers 18 h 30, Paul Mariani se trouvait à son domicile, (b) lorsque des gravillons ont été jetés contre la fenêtre. (adapted from (2))

We can control the proliferation of framing topics through the conditions required for triggering their introduction. In presence of sentence locative adverbials, framing topics are simply triggered by the compositional semantics of the adverbials. And as far as Background forward $_{\text {is }}$ concerned, we have seen that the introduction of the FT is triggered by the attachment of the eventive clause to the stative one. If we leave it simply as is, we will have two framing topics one on top of the other. We therefore propose a very simple modification to the content of 
the FT corresponding to a frame adverbial. We propose to demand the main eventuality to be an event, that is, (21) in Section 6.2 is slightly modified to:

$$
\exists P \exists e(P(e) \wedge \phi(e) \wedge \operatorname{Event}(e))
$$

This additional constraint on the type of the eventuality that can elaborate the topic prevents the stative clause from attaching to the adverbial FT with Elaboration, as the semantics of this relation forbids a state to be part of an event. In such a case, the constituent introducing the state will be simply treated as a regular Background of the scene, related with the corresponding relation to the FT. And the following eventive clause will correctly fill the empty slot in the Elaboration relation, as well as updating the variable $P$ in the FT. In a sense, this analysis ensures that the adverbial automatically becomes the FT of the forward-looking background which leads to the correct construction — with only one FT - in Figure 11.

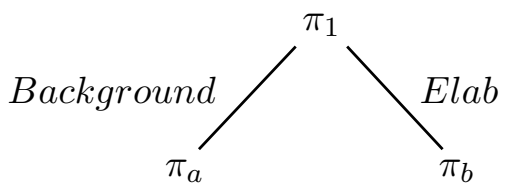

Figure 11: Structure for example (30)

\section{A complete example}

In this section we consider a more complete example featuring frame embedding, presuppositions and background/temporal adverbial interactions. In (32) the locating adverbials in IP-adjunct position are contributing to the understanding of the discourse. The relations between the four explicit temporal expressions (le 31 décembre, vers 18h30, un peu plus tard dans la soirée, le lendemain) help to build embedded or successive segments and a coherent interpretation for the discourse. Our proposal accordingly creates four framing topics $\left(\pi_{1}, \pi_{2}, \pi_{3}\right.$ and $\left.\pi_{4}\right)$ as illustrated in Figure 12, some of which also serve for backgrounding constructions $\left(\pi_{1}, \pi_{2}, \pi_{4}\right)$, as well as a general narrative topic $\left(\pi_{5}\right)$, standard in SDRT.

(a) Le 31 décembre PM se trouvait à son domicile de S., (b) lorsque vers 18 h 30, des gravillons ont été jetés contre la fenêtre. (c) Le village était alors plongé dans l'obscurité (d) en raison d'une coupure de courant. (e) PM sortit pour voir (f) et fut abattu sur le champ par un individu (g) qui se fondit rapidement dans la nuit. (h) Un peu plus tard dans la soirée les gendarmes sillonnèrent les alentours à la recherche des premiers indices. (i) Le lendemain, le village était encore sous le choc (j) quand ils commencèrent leurs interrogatoires.

The structure presented in Figure 12 leaves aside the treatment of presuppositions, of which there are many here. Possessives and definite descriptions son domicile, la fenêtre, les gendarmes, les indices ..., all trigger presuppositions. ${ }^{13}$ According to the proposal presented in Section 6.3, we have to insert as many new framing topics, and attach the presupposed content with Background and the proffered one with Elaboration. In our case, the nodes

\footnotetext{
${ }^{13}$ Le village is simply bound to the village $S$. introduced in $\pi_{a}$ and which percolates in the topic $\pi_{1}$.
} 


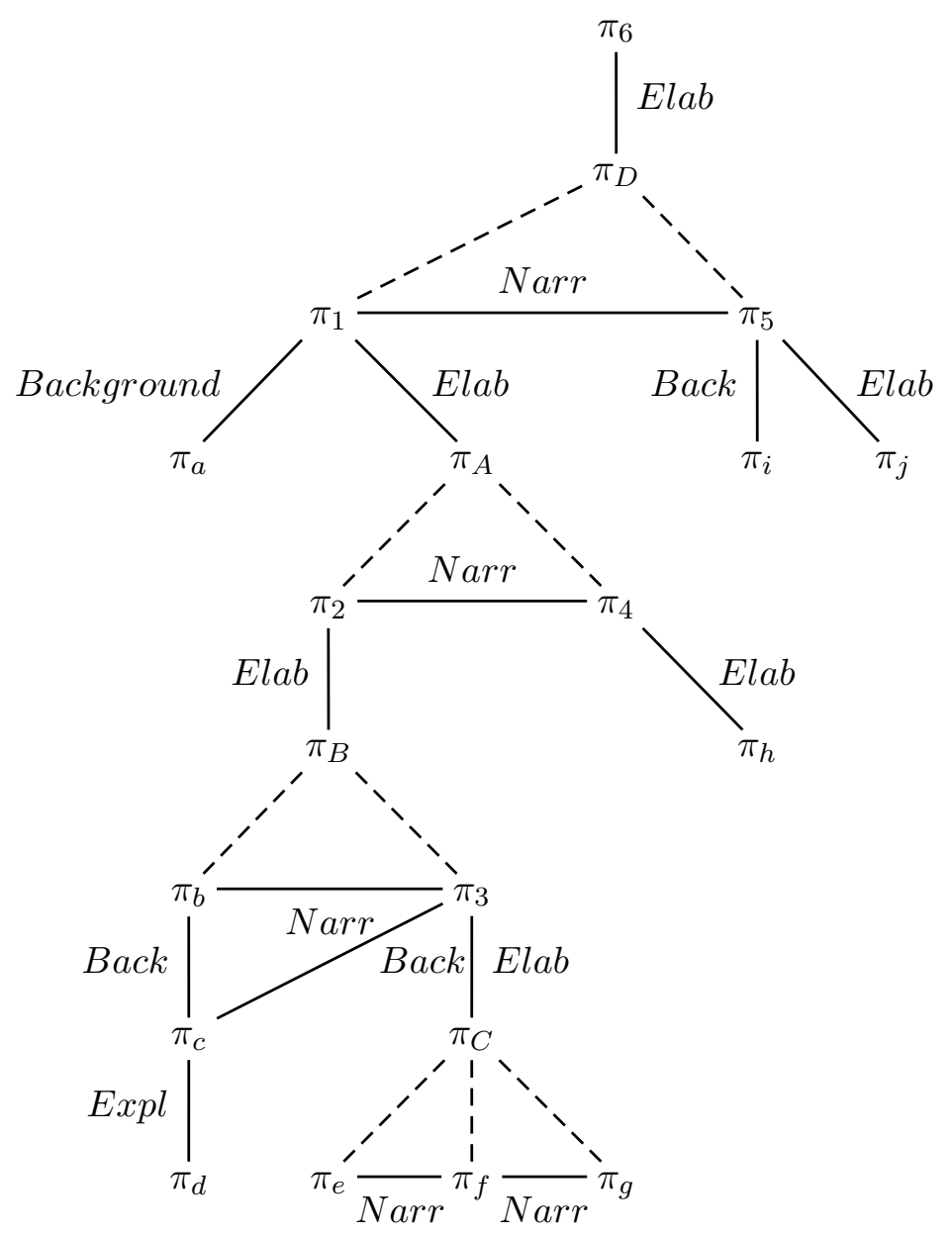

Figure 12: Structure for example (32) 
$\pi_{a}, \pi_{b}$, and $\pi_{h}$ would be replaced by topics associated with the Background and Elaboration relations over corresponding presupposed and proffered constituents. More precisely, at the content level and for the first two clauses we would get:

- $\pi_{a}: \exists x, s_{a}\left(\operatorname{State}\left(s_{a} \wedge\right.\right.$ be-at $\left.\left(s_{a}, P M, x\right)\right)$

- $\pi_{a-\text { pres }}:$ home $(x, P M)$

- $\pi_{a-p r o f}: \exists s_{a-p r o f}\left(\operatorname{State}\left(s_{a-p r o f}\right) \wedge\right.$ be-at $\left.\left(s_{a-p r o f}, P M, x\right)\right)$

- $\pi_{b}: \exists y, e_{b}, z\left(\operatorname{Event}\left(e_{b}\right) \wedge\right.$ throw-against $\left.\left(e_{b}, z, y\right)\right)$

- $\pi_{b-\text { pres }}: \exists u($ window $(y) \wedge \operatorname{Part-of}(y, u) \wedge u=x)$

- $\pi_{b-p r o f}: \exists e_{b-p r o f}\left(\operatorname{gravel}(z) \wedge \operatorname{Event}\left(e_{b-p r o f}\right) \wedge \operatorname{throw-against}\left(e_{b-p r o f}, z, y\right)\right)$

In the case of adverbials, as we have seen in the last section, the main eventuality of a framing topic is necessarily an event, but as we see here, in the case of presuppositions, it can also be a state since statives can introduce presuppositions.

This example raises another interesting issue, the relation between the different frames. Let us sum up the passage as four main moments corresponding to four framing topics: December 31 st $\left(\pi_{1}\right)$, $18 h 30\left(\pi_{2}\right)$, a little later $\left(\pi_{3}\right)$, the day after $\left(\pi_{4}\right)$. The relations between these framing topics are different, as exhibited in Figure 12: $\pi_{2}$ and $\pi_{3}$ are subordinated to $\pi_{1}$ while $\pi_{4}$ is subsequent. In terms of frames, we would say that the frames are respectively embedded and incompatible. This distinction might be marginal from a textual organization viewpoint which might consider all frames to be equal but it is essential for our purposes. In particular, we might use the frame organization to help us in determining the discourse structure, in particular discourse continuations and discourse pop-ups in presence of adverbials. On this issue, we share the same interest with discourse framing studies and use their results but we need to go further into spatio-temporal sophistication in order to reach our objective.

\section{Conclusion and Future work}

In this paper we proposed an homogeneous and intuitive proposal for the various kinds of Backgrounds occurring in discourse. Our solution features some significant improvements compared to previous formal attempts to model this discourse relation in SDRT. We propose to use a single Background relation instead of Background $d_{\text {backward }}$ and Background forward $_{\text {as }}$ it was done before. However, we still distinguish the two situations by differentiating the discourse structures in which the relation appears. A previous Background backward situation will simply introduce two constituents linked by the Background relation. A Background forward $_{\text {f }}$ situation will introduce a more complex structure with an additional framing topic constituent linked to the background by a Background relation and to the foreground by an Elaboration.

Some open issues remain to be addressed. Some are rather technical ones like the precise management of discourse referents whose introduction location changes during the construction process because of the appearance of constructed constituents (such as framing topics). Some are more global discourse issues that concern all levels and approaches 
of discourse - for example, determining the scope of discourse frames, i.e., in this approach, the scope of framing topics. However, our analysis did take advantage of recent work on framing adverbials. We hope this paves the way for a deeper integration with macro-level studies such as [Charolles, 1997, Le Draoulec and Péry-Woodley, 2001, Le Draoulec and Péry-Woodley, 2005], which should facilitate the identification of frame boundaries and discourse pop-ups.

\section{Acknowledgments}

We would like to thank Myriam Bras, Marie-Paule Péry-Woodley and Marianne Vergez-Couret for discussions related to the content of this paper, Laure Sarda for her patience during the editing process, and Shirley Carter-Thomas and two anonymous reviewers for their useful comments which improved the content and the understandability of this paper.

\section{References}

[Asher, 1993] Asher, N. (1993). Reference to Abstract Objects in Discourse. Kluwer Academic Publisher.

[Asher, 2004] Asher, N. (2004). Discourse topic. Theoretical Linguitics, (30):161-201.

[Asher et al., 1995] Asher, N., Aurnague, M., Bras, M., Sablayrolles, P., and Vieu, L. (1995). De l'espace-temps dans l'analyse du discours. Sémiotique, 9:11-63.

[Asher and Gómez Txurruka, 1995] Asher, N. and Gómez Txurruka, I. (1995). Extending SDRT to integrate a theory of the informational partition. Technical report, ILCLI.

[Asher et al., 2001] Asher, N., Hardt, D., and Busquets, J. (2001). Discourse parallelism, ellipsis, and ambiguity. Journal of Semantics, 18(1).

[Asher and Lascarides, 1998] Asher, N. and Lascarides, A. (1998). The semantics and pragmatics of presupposition. Journal of Semantics, 15(3):239-300.

[Asher and Lascarides, 2003] Asher, N. and Lascarides, A. (2003). Logics of conversation. Cambridge University Press.

[Asher and Vieu, 2005] Asher, N. and Vieu, L. (2005). Subordinating and coordinating discourse relations. Lingua, 115(4):591-610.

[Beaver, 1997] Beaver, D. (1997). Presupposition. In van Benthem, J. and ter Meulen, A., editors, The Handbook of Logic and Language, pages 939-1008. Elsevier.

[Busquets et al., 2001] Busquets, J., Vieu, L., and Asher, N. (2001). La SDRT : une approche de la cohérence du discours dans la tradition de la sémantique dynamique. Verbum, 22(1):73-102.

[Carlson and Marcu, 2001] Carlson, L. and Marcu, D. (2001). Discourse tagging manual. Technical Report ISI-TR-545, ISI. 
[Charolles, 1997] Charolles, M. (1997). L'encadrement du discours: univers, champs, domaines et espaces. Cahier de Recherche Linguistique, 6:1-73.

[Fabricius-Hansen et al., 2005] Fabricius-Hansen, C., Ramm, W., Solfjed, K., and Behrens, B. (2005). Coordination, discourse relations and information packaging - cross-linguistic differences. In Aurnague, M., Bras, M., Le Draoulec, A., and Vieu, L., editors, First International Symposium on the Exploration and Modelling of Meaning, pages 85-93.

[Grosz et al., 1995] Grosz, B., Joshi, A., and Weinstein, S. (1995). Centering: a framework for modelling the local coherence of discourse. Computational Linguistics, 21(2):203-225.

[Gundel et al., 1993] Gundel, J., Hedberg, N., and Zacharski, R. (1993). Cognitive status and the form of referring expressions in discourse. Language, 69(2):274-307.

[Hobbs, 1979] Hobbs, J. R. (1979). Coherence and coreference. Cognitive Science, 3:67-90.

[Hovy and Maier, 1995] Hovy, E. and Maier, E. (1995). Parsimonious or profligate: How many and which discourse structure relations? Unpublished ms.

[Hovy, 1990] Hovy, E. H. (1990). Approaches to the planning of coherent text. In Paris, C., Swartout, W., and Mann, W., editors, Natural Language in Artificial Intelligence and Computational Linguistics, pages 83-102. Boston:Kluwer.

[Hunter et al., 2006] Hunter, J., Asher, N., Reese, B., and Denis, P. (2006). Evidentiality and intensionality: Two uses of reportative constructions in discourse. In Sidner, C., Harpur, J., Benz, A., and Kühnlein, P., editors, Proceedings of the Workshop on Constraints in Discourse, pages 99-106, National University of Ireland, Maynooth.

[Johnston, 1994] Johnston, M. (1994). The syntax and the semantics of adverbials adjuncts. $\mathrm{PhD}$ thesis, University of California at Santa Cruz.

[Kamp and Reyle, 1993] Kamp, H. and Reyle, U. (1993). From Discourse to Logic. Kluwer Academic Publishers.

[Knott, 1996] Knott, A. (1996). A Data-Driven Methodology for Motivating a Set of Coherence Relations. PhD thesis, Department of Artificial Intelligence, University of Edinburgh.

[Lascarides and Asher, 1993] Lascarides, A. and Asher, N. (1993). Temporal interpretation, discourse relation and commonsense entailment. Linguistics and Philosophy, 16:437-493.

[Le Draoulec and Péry-Woodley, 2001] Le Draoulec, A. and Péry-Woodley, M.-P. (2001). Corpus-based identification of temporal organization in discourse. In Proceedings of Corpus Linguistics, pages 159-166.

[Le Draoulec and Péry-Woodley, 2005] Le Draoulec, A. and Péry-Woodley, M.-P. (2005). Encadrement temporel et relations de discours. Langue Française, 148:45-60.

[Maienborn, 1995] Maienborn, C. (1995). Toward a compositional semantics for locative modifiers. In Proceeddings of Semantics and Linguistic Theory V, pages 237-254.

[Mann and Thompson, 1987] Mann, W. and Thompson, S. (1987). Rhetorical structure theory: a theory of text organization. Technical report, Information Science Institute. 
[Marcu, 1997] Marcu, D. (1997). The Rhetorical Parsing, Summarization, and Generation of Natural Language Texts. PhD thesis, Department of Computer Science, University of Toronto.

[Marcu, 2000] Marcu, D. (2000). The Theory and Practice of Discourse Parsing and Summarization. MIT Press.

[Paris, 1990] Paris, C. L. (1990). Generation and explanation: Building an explanation facility for the explainable expert systems framework. In Paris, C., Swartout, W., and Mann, W., editors, Natural Language in Artificial Intelligence and Computational Linguistics, pages 49-82. Boston: Kluwer.

[Prévot, 2004] Prévot, L. (2004). Structures sémantiques et pragmatiques pour la modélisation de la cohérence dans des dialogues finalisés. PhD thesis, Université Paul Sabatier.

[Prince, 1981] Prince, E. (1981). Toward a taxonomy of given-new information. In Cole, P., editor, Radical Pragmatics, pages 223-255. Academic Press, New York.

[Reese et al., 2007] Reese, B., Denis, P., Asher, N., Baldridge, J., and Hunter, J. (2007). Reference manual for the analysis and annotation of rhetorical structure (v 1.0). Technical report, University of Texas at Austin.

[Roussarie, 2000] Roussarie, L. (2000). Un modèle théorique d'inférence de structures sémantiques et discursives dans le cadre de la génération automatique de texte. $\mathrm{PhD}$ thesis, Université Denis Diderot, Paris 7.

[Sarda, 2005] Sarda, L. (2005). Fonctionnement des cadres spatiaux dans les résumés de films. Langue Française, 148:61-79.

[Steedman and Kruijff-Korbayova, 2001] Steedman, M. and Kruijff-Korbayova, I. (2001). Two dimensions of information structure in relation to discourse semantics and discourse structure. In Kruijff-Korbayova, I. and M.Steedman, editors, Proceedings of the ESSLLI'01 Workshop Information Structure, Discourse Structure and Discourse Semantics, pages 1-9, University of Helsinki.

[Taboada and Mann, 2006] Taboada, M. and Mann, W. (2006). Rhetorical Structure Theory: Looking back and moving ahead. Discourse Studies, 8(3).

[Vallduví, 1994] Vallduví, E. (1994). The dynamics of information packaging. Technical report, CSHRC.

[van der Sandt, 1992] van der Sandt, R. (1992). Presupposition projection as anaphora resolution. Journal of Semantics, 9:333-377.

[Vieu et al., 2005] Vieu, L., Bras, M., Asher, N., and Aurnague, M. (2005). Locating adverbials in discourse. French Language Studies, 15:173-193.

[Vieu et al., 2006] Vieu, L., Bras, M., Le Draoulec, A., and Asher, N. (2006). Adverbiaux de localisation comme introducteurs de topiques de discours. In Quatrièmes Journées Sémantique et Modélisation, pages 43-44. 
[Vieu and Prévot, 2004] Vieu, L. and Prévot, L. (2004). Background in Segmented Discourse Representation Theory. In Workshop Segmented Discourse Representation Theory, 11th conference on Natural Language Processing (TALN), pages 485-494. 